\title{
THE PRE-HISTORY OF CRYOSCOPY: WHAT WAS DONE BEFORE RAOULT?
}

\author{
Simón Reif-Acherman \\ Escuela de Ingeniería Química, Universidad del Valle, A.A. 25360 Unicentro Cali - Colombia
}

Recebido em 17/7/08; aceito em 10/2/09; publicado na web em 3/7/09

\begin{abstract}
Cryoscopy is considered one of the foundations of the modern theory of solutions and of physical chemistry. This paper shows in order the first regularities pointed out by several scientists on the subject, in the first chapter of its birth as a scientific discipline. The study is focused on the identification of the different steps that helped, first qualitatively and then quantitatively, to adjust the different classes of possible solutions, including those that formed hydrates, to a basic formulation that the French scientist François-Marie Raoult would later generalize in the law that bears his name.
\end{abstract}

Keywords: cryoscopy; history; freezing point.

The excessively brief style used by most textbooks to present the historical events associated with the emergence, development, and discussion of laws, theories and hypotheses related to scientific concepts, usually tends to create in the reader a distorted or incomplete version of the real facts. The history of cryoscopy's birth as a scientific discipline constitutes a good example of this situation.

Cryoscopy is usually defined as the branch of science that studies the solutions founded on the determination of their corresponding freezing points. It allows, just like the other colligative properties, the determination of the molecular weight of a an unknown or unidentified substance based on the principle that the freezing point of a solution compared with that of the respective solvent varies according to the amount and nature of the solute dissolved in it. The origins of cryoscopy (from Greek roots, $\kappa \rho v o \varsigma$ ice, and $\sigma \kappa о \pi \varepsilon \omega$ I examine) have been generally associated, in an almost exclusive way, with the name of the French professor of chemistry François-Marie Raoult (1830-1901). Through a very accurate and systematic experimental work on this subject, he was able to formulate a freezing point law that holds not only for water but also for other solvents, which include solutes of both, organic and inorganic nature. The very little cited information included in textbooks on physical chemistry about the different colligative properties seems to show that Raoult was gifted with the relevant information. According to that, it wouldn't be possible to know that the subsequent evolution of the subject was the result of many trials, successes, failures, approximations, and mistakes. Although it is true that he was responsible not only for the quantitative generalization of the connection between the lowering of freezing point of a solution and its corresponding concentration, but also for the proposal of the name for this branch of chemistry, the first observations about this subject go back to more than a century before Raoult's researches.

The purpose of this article is show in order the first regularities pointed out by several scientists on the subject, which would later lead to the formulation of what could be considered one of the foundations of the modern theory of solutions and of physical chemistry. The specific nomenclature used by each one of the involved scientists has been preserved as far as it has been possible with the purpose to support the presentation of extracts of the original papers, in spite of some confusion it could cause.

*e-mail: sireache@univalle.edu.co

\section{FIRST OBSERVATIONS}

The effect of the presence of solutes in the solutions' behaviour and some characteristics of their crystallization was qualitatively observed in the eighteenth century, but no one quantitative study was undertaken at that time. Some few commentaries by the Dutch-born mathematician David Bernoulli (1700-1782) in his work Hydrodynamica about the reasons that would explain the effect of sugar and salts in the lowering of the freezing point of water seem to constitute one of the first references to the subject. ${ }^{1} \mathrm{He}$ attributed to the 'foreign' particles interposed between the aqueous particles the responsibility for the reduction of the attraction between them and the consequent possibility to remain together (particulis aqueis interpositæ, harum attractionem diminuant, neque hæ conjungi possint), and mentioned the feasibility to get a pure compound through the freezing of such solutions (tempore congelationis fit quædam partium ex poris expulsio, seu secretion atque præcipitatio). ${ }^{2}$

The first reported experimental research on freezing points of solutions was carried out by the clergyman and professor of chemistry at the University of Cambridge, Richard Watson (1737-1816), Figure 1. Although Watson's scientific interests were mainly focused on different quantitative problems of physical chemistry and applications of chemical research to metallurgy and industry, his most original work very probably was on the phenomena of solutions, and, specifically, on the study of the effects of the addition of different amounts of several salts on some specific properties of the corresponding solutions. ${ }^{3,4} \mathrm{~A}$ glance at his few publications on the subject shows a great tendency to find out relationships of continuity of several of the involved va-

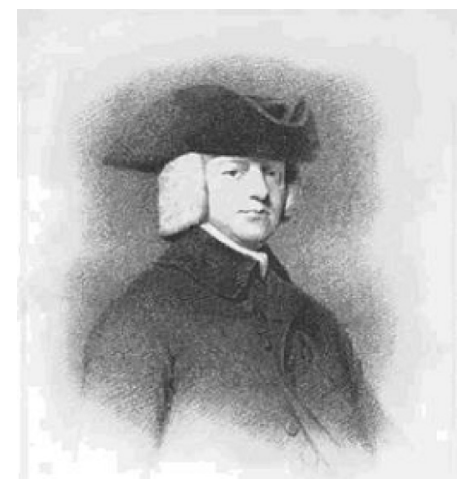

Figure 1. Portrait of Richard Watson ${ }^{4}$ 
riables between the property value of the pure solvent and that of the solution. Shortly after the experimental results of his first research proved that solution of salts is accompanied by an increase in volume and in specific gravity of the liquid, in an opposite way to the beliefs of those times, Watson found himself involved in an unplanned way in a new research related with the freezing point of solutions. ${ }^{5}$

Taking advantage of very uncommon circumstances of intense cold in Cambridge (approximately $-14{ }^{\circ} \mathrm{C}$ ) on February 12, 1771, Watson hastened to go to his laboratory trying to find out some useful information about the effect of this climatic phenomenon upon the freezing point of saturated solutions of eighteen different salts he had then there available. The preparation of all solutions had been very similar; it meant with equal mass proportions of salts and water, and, once all they had reached the same temperature, had been exposed in vessels of equal shape and size to the same freezing atmosphere. An analysis of his first set of experimental essays allowed him to make the first significant contribution to the subject. Taking watchful note of the different times when the water in each one of the solutions began to change its state, he was able to identify the influence of the solute's nature as the responsible variable of their different behaviours. In his own words, "by this comparison of equal quantities of different salts dissolved in equal quantities of water, we might be enabled to speak with as much precision, concerning the powers by which they resist congelation, as we do concerning those by which they resist putrefaction." This conclusion led him to suggest a way to classify the solutions, ordering them according to their corresponding freezing point, or to what he called "the relative powers of neutral salts in resisting congelation". 6

Watson's most significant finding happened while experimenting with mixtures of different proportions of the same pair of compounds, water and sea salt, concluding that "in salt of the same kind, the resistance to congelation is the direct simple proportion of the quantity of salt dissolved". He added that "this conclusion cannot be extended to salts of different kinds, since water saturated with sea salt is more difficultly congealed than when saturated with various other salts, which it dissolves in greater quantities". Considering the great difference between the room temperature and the freezing point of water, the times evaluated by Watson constituted closely proportional values to the corresponding depressions of the freezing points of the different solutions. This circumstance led him to be the first one to suggest a clear proportionality relation between a basic property of a solution -the concentration- and its corresponding depression of the freezing point.

\section{THE BASIC STATEMENT: BLAGDEN'S LAW}

Almost two decades later, another British scientist, the physician Sir Charles Blagden (1748-1820), took up again the subject. ${ }^{7}$ Blagden, Figure 2, had been assistant to the physicist and chemist Henry Cavendish (1731-1810) for seven years, and his interests in the study of freezing of solutions were very probably influenced by the latter's previous researches on the caloric and volumetric effects associated with this same subject. ${ }^{8}$

Blagden undertook in 1788 the study of the effect of different dissolved inorganic substances in the lowering of freezing point of water $^{9}$ as a continuation of previous investigations on the phenomena of the supercooling of water. ${ }^{10}$ The main objective of the researches, characterized by a strict methodology and a full and deep analysis of the experimental results, was the determination of the lowering of the freezing points of solutions with the addition of equal quantities of different substances. The experimental procedure was too simple to be carried out, without special care requirements or instruments. The solutions were prepared by dissolving each one of the selected solutes in distilled water, and in various proportions. Then, each solution was put into a glass tumbler, at a level two or three inches above the bottom, which was subsequently immersed in a mixture of common salt and ice (or snow), and the corresponding freezing points were measured. Although it seems he intended to work with equal mass proportions of all solutes, he was unable to do so because of their different solubilities in water.

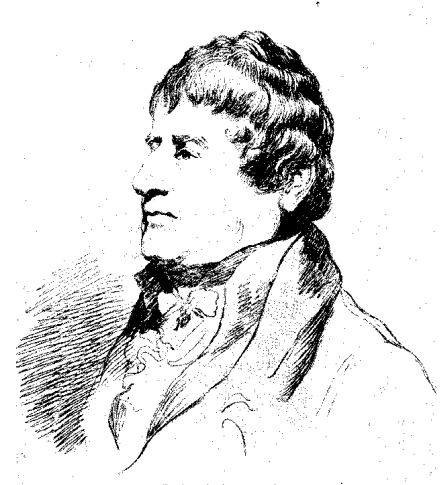

Figure 2. Portrait of Sir Charles Blagden ${ }^{7}$

Blagden initially experimented with solutions of different concentrations of several solutes that he called 'neutral' salts with the purpose to find out a "ratio according to which equal additions of the same substance depress the freezing point", determining for each one the difference between its corresponding freezing point and that of water. The studied solutes were: common salt, nitre (potassium nitrate), sal ammoniac (ammonium chloride), Rochelle salt (potassium sodium tartrate), salt catharticus amarus (magnesium sulphate), green vitriol (heptahydrate of ferrous sulphate), and white vitriol (heptahydrate of zinc sulphate). His results quantitatively confirmed, within the limits of experimental error, Watson's previous conclusions, excluding those obtained with solutions whose concentrations were greater than that corresponding to saturation for each solute. Blagden then wrote: "the salt lowers the freezing point in the simple inverse ratio of the proportion which the water bears to it in the solution". Nevertheless, he didn't make any reference to Watson's researches in his report. Besides the quantitative treatment, the main original addition Blagden made was the generalization he noticed about that the quotient (that he just named ratio) between the depression in the freezing point and the amount of dissolved salt was nearly in a simple ratio. In mathematical terms,

$$
\frac{C}{P}=K
$$

where $C$ and $P$ are the depression in the freezing point of the solution and the quantity of added salt, respectively, and $K$ a specific constant for each solute. From those times, this relationship was widely known as Blagden's law.

Table 1, a and b, allows one to observe the validity of Blagden's conclusions for several proportions water: salt with two specific solutes, common salt and ammonium chloride. The values shown in the second and third columns represent the freezing points for each solution experimentally determined and calculated by Blagden (according to the relation he found with the exception of those situations where the salt's contents exceeded the solubilities, and there was precipitation), respectively.

Motivated by his results, Blagden attempted unsuccessfully to study two additional, but related subjects. The first proposed objective was to confirm if the effect of the addition of a second salt on the 
freezing point of a previously formed saturated solution would be to lower it - the same number of degrees that an equal proportion of the same salt would do it with the freezing point of water. After working with different pairs of solutes, he was unable to reach a definitive conclusion about this point.

Table 1. Blagden's results for solutions with (a) common salt and (b) ammonium chloride ${ }^{9}$

\section{Common Salt}

\begin{tabular}{|c|c|c|}
\hline $\begin{array}{l}\text { Proportion } \\
\text { of water to } \\
\text { the falt, }\end{array}$ & $\begin{array}{c}\text { Freezing } \\
\text { point by the } \\
\text { experiment. }\end{array}$ & $\begin{array}{l}\text { Freczing } \\
\text { point by cal- } \\
\text { culation. }\end{array}$ \\
\hline $\begin{array}{l}3^{2}: 1 \\
3^{2}: 1\end{array}$ & $\begin{array}{l}29 \\
28+\end{array}$ & $\begin{array}{l}28 \frac{1}{2} \\
28 \frac{1}{2}\end{array}$ \\
\hline $24: I$ & $27 / \frac{\pi}{2}$ & 275 \\
\hline $16: I$ & $25^{\frac{\pi}{4}}$ & 25 \\
\hline IO: I & $21 \frac{\pi}{2}$ & 207 \\
\hline $7,8: \mathrm{r}$ & $18 \frac{1}{2}$ & $17 \frac{2}{3}$ \\
\hline $6,2: 1$ & $\mathbf{I}^{3} \underline{x}^{2}$ & 14 \\
\hline $5: 1$ & $9 \frac{\pi}{2}$ & $9^{\frac{\pi}{2}}$ \\
\hline $5,5: I$ & $7 \frac{x}{5}$ & 7 \\
\hline $4: 1$ & 4 & 4 \\
\hline
\end{tabular}

(a)
Sal ammoniac

\begin{tabular}{|c|c|c|}
\hline $\begin{array}{l}\text { Froportion } \\
\text { of water to } \\
\text { the fali. }\end{array}$ & $\begin{array}{l}\text { Freezing } \\
\text { point by the } \\
\text { experiment. }\end{array}$ & $\begin{array}{l}\text { Freezing point } \\
\text { by calculation. }\end{array}$ \\
\hline I $5,7: 1$ & $24 \frac{\pi}{2}$ & $24 \frac{1}{3}$ \\
\hline $10: 1$ & $20 \frac{\pi}{2}$ & 20 \\
\hline $9,8: \mathbf{I}$ & 20 & I $9 \frac{3}{4}$ \\
\hline $7,9: 1$ & $16 \frac{\pi}{2}$ & $16 \frac{1}{4}$ \\
\hline $6: 1$ & 12 & 12 \\
\hline $5: 1$ & 8 & 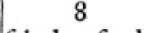 \\
\hline $4: 1$ & 4 & falt depofited \\
\hline
\end{tabular}

(b)
The other subject was related with the study of freezing points of solutions formed by water and substances, such as acids, alkalis, and 'spirit of wine'. According to the obtained results, he concluded that the effect of equal additions of this class of substances was similarly to lower the freezing point of water, but in an increasing ratio instead a constant one. Table 2, a and b, show the particular results corresponding to different proportions water : muriatic acid and water : mineral alkali (sodium hydroxide), respectively.

Table 2. Blagden's results for aqueous solutions of (a) muriatic acid and (b) mineral alkali ${ }^{9}$
Muriatic acid.

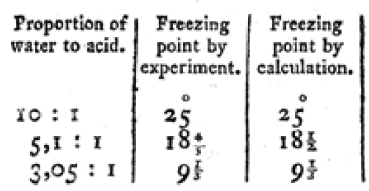

(a)
Mineral Alkali.

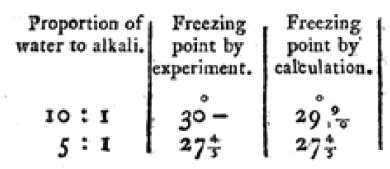

(b)
Blagden related these results with the strong attraction these substances showed for water. He was firmly convinced that a different new law should apply to each one of these situations, although this time he didn't suggest anything.

The Blagden's general achievement was fortunate to some extent. The strong electrolytes he chose as solutes for the experimentation could to have easily ruined the possibilities for finding a general relationship, and the only possibility to avoid it, which was the theory of electrolytic dissociation, would take still a century to be proposed. Blagden would not have been able to generalize the effect of the salts if, for an example, he had studied more diluted solutions and used a more finely graduated thermometer. The ignorance by that time of the dependence of the dissociation degree on the nature of the substance and its concentration in the solution, being more developed the greater the dilution, had been a definitive limitation. The discovery of the influence the electrolytic dissociation has on the lowering of the freezing point, the increase of the boiling point and the osmotic pressure of solutions containing electrolytes, could have helped to explain the seemingly anomalous results Blagden had found at working with acid and alkaline solutions.

\section{EXTENSIONS AND NEW TERMS}

Several later quantitative researches confirmed Blagden's generalization. Most of the new results mainly emerged as a secondary consequence to researches that combined efforts on three common fronts: studies on the variations of volume of different liquids with temperature, mainly those of water and aqueous solutions, the development of new techniques for temperature measurements, and the appropriate understanding of the basic principles of crystallization.

The interest of the scientific community at that time in the evaluation of the volumetric properties of different salt solutions was related not only to simultaneous researches on the temperature of the sea at different depths, but also to their then proposed possible experimental uses, particularly as refrigerant mixtures. Some scientists began to suspect that water behaved anomalously in two respects in the small temperature range between 0 and about $4{ }^{\circ} \mathrm{C}$. Its expansion upon freezing and the increase of its density with temperature over this range became usual research subjects. No one was sure of this behavior, though, or understood possible reasons for it. The definitive confirmation in 1805 of the existence of the density maximum of pure water by the Scottish chemist Thomas Charles Hope (1766-1844) encouraged new studies on the subject, which quickly extended to cover aqueous solutions with similar behaviour. ${ }^{11}$ They contributed even more to the necessity to have precise instruments for measurements of both pressure and temperature in order to reach the required results. The knowledge, for example, of the dilatation of mercury, was then indispensable in barometric observations, ${ }^{12}$ and, through it, a great number of other situations, such as the determination of the dilatation of glass and several metals. Likewise, the increasing number of researches on low temperatures ${ }^{13}$ also required the utilization of appropriate thermometric liquids, whose behaviours with changes of temperature were clearly known in those new ranges. ${ }^{14}$ On the other front, the general studies on crystallization helped not only to understand the basic mechanisms that governed the process, but also the conditions under which it happened and the possibility to predict some of the results. ${ }^{15}$

The researches of the Belgian-born, naturalized Frenchman, professor of physics César Mansuète Despretz (1789-1863) continued this course of work. ${ }^{16}$ Following a similar previous research with pure water, he proved that all salt solutions had a maximum density, and that the temperature which is reached for each one of them was function of its corresponding composition. ${ }^{17}$ Despretz noticed too that the lowerings caused in that temperature by the addition of amounts of solute were always greater than those in their corresponding freezing points, and that in both situations there were proportionality relationships between these reductions and the concentrations of the dissolved substance. In this way, he not only endorsed Blagden's conclusions, but formulated a new generalization with a law that still today bears his name.

A subsequent investigation carried out by the Swiss professor at the Academy of Laussane, Louis Dufour (1832-1892), with the main purpose to determinate the nature and degree of separation reached between solid and liquid phases during the freezing process of aqueous solutions, indirectly allowed the confirmation of the conclusions reached by Blagden. It, nevertheless, didn't make any additional and significant contribution to the subject. ${ }^{18}$

Bearing in mind that some of Despretz's conclusions were not supported by experimental verification, the professor of physics at the University of Padua, Francesco Rossetti (1833-1885), attempted to provide such evidence following a suggestion of the chemist and physicist Henri Victor Regnault (1810-1878), who started him out in researches 
on this subject. ${ }^{19} \mathrm{He}$ carried out a series of some experimental studies at the Collège de France, at Paris, on the exact determination of the density behaviour of distilled water and some salt and alcoholic solutions and their variation with temperature, attempting to link the results with the behaviour of the depressions of the corresponding freezing points. ${ }^{20}$

The Table 3 shows the results reported by Rossetti for eight different solutions of sodium chloride in distilled water and for sea water at two different seasons (with high tide). There, $A$ represents the differences between the temperatures of maximum density for each solution and that for pure water, $C$ the lowering in the freezing point (or what it is the same, the freezing point of each solution in relation to $0{ }^{\circ} \mathrm{C}$ for pure water), and $P$ again the amount of dissolved solute. Rossetti clearly noticed that whereas the second ratio, $C / P$, looked nearly constant for all the solutions, the first one, $A / P$, changed slowly and gradually, which suggested him the possibility to find in this phenomenon a general law about the solutions' behaviour. It was later confirmed through similar researches, which additionally showed that the lowering of the temperature of maximum density, unlike that of freezing point, didn't depend solely on the weight of the dissolved substance, but also of its nature.

Whereas the application of Blagden's relation was verified exactly for aqueous solutions of some salts, there were others whose specific constant $K$ always increased with $P$. It was the German scientist and Gustav Magnus's assistant at the University of Berlin, Friedrich Rüdorff (1832-1902), who found the key to solve this apparent difficulty focusing on the constitution of salt solutions, apparently without knowing what had been done by Blagden seven decades before. ${ }^{21} \mathrm{He}$ suggested that whereas the solutes in the first group of solutions remained in their natural condition once dissolved in water, those in the second group combined with some definite amounts of water to form hydrated compounds. Remarking the necessity to distinguish between these two classes of solutions, Rüdorff extended the Blagden's results by including the second group, considering that those definite quantities of water - the so-called waters of crystallization - were integral parts of the dissolved substance. In this way, he modified the composition term in the original relation's statement, by including the weight of the full hydrate to be created, instead that of the anhydrous solute.

Working independently of other researchers, Rüdorff sent in 1860 a first communication to the Academy of Sciences of Berlin about his experiments with solutions prepared with chlorides, nitrates, and carbonates. $^{22}$ To obtain the lowering of the freezing point of specific solutions with hydrated salts, he suggested to multiply the weight of the added amount of the full salt in one hundred grams of water, $P^{\prime}$, by a specific constant, $K$, for each solution. He named this constant a lowering or depressing coefficient. Mathematically expressed,

$C=K P^{\prime}=K\left[\frac{(P+p) 100}{100-p}\right]$

where $P$ and $p$ represent the weight in grams of salt in anhydrous condition added to one hundred grams of water, and that of the accompanying water to form with it a definite hydrate, respectively; and $C$ the freezing point depression as before. In this way, the lowering coefficient took the form

$$
K=\frac{C}{100(P+p) /(100-p)}=\frac{C(100-n P)}{100 P(1+n)}
$$

where $K$ was now a constant independent of the concentration while the hydrate didn't decompose, and $n(=\mathrm{p} / \mathrm{P})$ represented the number of 'equivalents of water of hydration' (as it was then called) or the actual amount of water molecules that combined with one mol of solute to form the specific hydrate. The original Blagden's ratio could be expressed then as:

$$
\frac{C}{P^{\prime}}=\frac{p}{100 P} C+K\left(\frac{p}{P}+1\right)=\frac{n}{100} C+K(n+1)
$$

$(\mathrm{n} / 100)$ being the tangent of the angle formed between the straight line at plotting $C / P$ 'against $C$, and the axis $x$. It was clear that the

Table 3. Rossetti's results for eight sodium chloride solutions ${ }^{20}$

\begin{tabular}{|c|c|c|c|c|c|c|c|}
\hline $\begin{array}{c}\text { Polns } \\
\text { pat iso. } \\
\qquad P\end{array}$ & $\begin{array}{c}\text { DESEITE } \\
\text { i zzers. } \\
d_{0}\end{array}$ & $\begin{array}{c}\text { Drvite } \\
\text { animum. } \\
d^{\mathrm{T}}\end{array}$ & 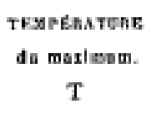 & 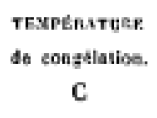 & 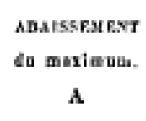 & $\frac{A}{p}$ & $\frac{\mathrm{C}}{p}$ \\
\hline$a^{\text {prasumes }}$ & 1,000000 & $1,000,30$ & $\begin{array}{r}4^{n} \\
+400\end{array}$ & 0,00 & $-0,00$ & $-n$ & $w$ \\
\hline 0,5 & 1,001925 & 1.007058 & $+3,00$ & $-0,32$ & $-1,00$ & $-2,00$ & $-0,04$ \\
\hline$:$ & $1,00=034$ & $1,00,660$ & $+1,77$ & $-0,65$ & $-2,23$ & $-2,23$ & $-0,65$ \\
\hline 2 & 1,015360 & 1,015367 & $-0,58$ & $-1,27$ & $-4,58$ & $-2,20$ & $-0,63$ \\
\hline 3 & $1,0,3530$ & 1,023543 & $-3,24$ & $-1,90$ & $-7,24$ & $-2,41$ & $-0,63$ \\
\hline 4 & 1,070660 & 1,030590 & $-5,63$ & $-2,60$ & $-9,63$ & $-2,4$ & $-0,65$ \\
\hline 6 & $1,04 \log _{97}$ & 1.04ig $5 x$ & $-11,07$ & $-3,91$ & $-15,07$ & $-2,51$ & $=0,6.5$ \\
\hline 7 & $"$ & & $-13,69$ & $-4,60$ & $-17,619$ & $-2,53$ & $-0,65$ \\
\hline 8 & $"$ & 1,0603102 & $-16,62$ & $-5,12$ & $-20,6 x$ & $=-2,55$ & $-0,6 i$ \\
\hline 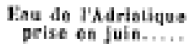 & $1,0 x 6695$ & 1,026754 & $-3,21$ & $-1,9^{\circ}$ & $\Rightarrow$ & if & $"$ \\
\hline 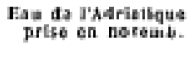 & $1,0281\{1\}$ & 1,0982614 & $-3,9^{0}$ & $-3,10$ & " & st & $"$ \\
\hline Valaur woymat. & 1,027470 & $\pi$ & $m$ & $n$ & $"$ & $-n, 4^{3}$ & $-0,64$ \\
\hline
\end{tabular}

Solutions do ehloriere de sodinm. 
equation only could to be applied if the exact formula of the hydrate (or equivalently the value of $n$ ) was previously known.

The use of a modified composition for this class of solutions didn't only maintain the validity of the mathematical relation, but extended its generality to all the aqueous solutions. Using the author's own nomenclature, table 4 shows the results reported by Rüdorff from working with different solutions of calcium chloride (in the notation he used, $M$ and $M_{1}$ had the same meanings as $P$ and $P^{\prime}$, respectively, while $T$ represented the freezing point lowering).

Table 4. Rüdorff's results for five different solutions of calcium chloride $^{22}$

\begin{tabular}{|c|c|c|c|c|}
\hline $\mathbf{M}$ & $\mathbf{M}_{i}$ & $\mathbf{T}$ & $\frac{\mathrm{T}}{\mathrm{MI}}$ & $\frac{\mathrm{T}}{\mathbf{M}_{1}}$ \\
\hline $\begin{array}{l}2 \\
4 \\
8 \\
14 \\
18\end{array}$ & $\begin{array}{r}4,02 \\
8,21 \\
37,70 \\
31,89 \\
43,05\end{array}$ & $\begin{array}{r}0 \\
0,100 \\
1,85 \\
3,90 \\
7,40 \\
10,00\end{array}$ & $\begin{array}{l}0,450 \\
0,457 \\
0,557 \\
0,528 \\
0,555\end{array}$ & $\begin{array}{l}0,274 \\
0,225 \\
0,325 \\
0,232 \\
0,271\end{array}$ \\
\hline
\end{tabular}

The degree of generalization reached by Rüdorff's results was so great that the stated relation even covered those solutions whose behaviours changed with their concentration's range. The aqueous solutions of sodium chloride constituted a simple example. Unlike calcium chloride, the hydrates formed with this salt were unstable over the full range of compositions, being quickly destroyed at temperatures above $-9{ }^{\circ} \mathrm{C}$. So, the corresponding freezing point lowerings were proportional to the weight of anhydrous salt at higher temperatures, and to that of the new formed compound at lower values. In this way, Rüdorff found a Blagden's ratio of 0.600 for solutions whose values of $P$ were lower than 14, and a depressing coefficient of 0.342 for those more concentrated, in which the hydrated compound $\mathrm{NaCl} \cdot 2 \mathrm{H}_{2} \mathrm{O}$ was formed, as is shown in Table 5 . Even recognizing some very little inaccuracies in Rüdorff's figures, both data sets clearly showed that while the respective original ratios quickly increased with $P$ (or $M$ in the alternate nomenclature), the corresponding lowering coefficients were nearly constant.

Perhaps the more interesting cases Rüdorff included in his studies were the cupric chloride solutions. Upon finding two different values for $K$, he concluded that an initially formed hydrate, $\mathrm{CuCl}_{2} \cdot 12 \mathrm{H}_{2} \mathrm{O}$, changed to a new compound, $\mathrm{CuCl}_{2} \cdot 4 \mathrm{H}_{2} \mathrm{O}$, with increasing solute composition. Although this hypothesis turned out to be correct, the problem was later taken up again and studied in detail.

Working on the same subject, Rüdorff proposed the mathematical expression

$$
n=\frac{100 P M\left(M^{\prime} C^{\prime \prime}-M^{\prime \prime} C^{\prime}\right)}{9 M^{\prime} M^{\prime \prime}\left(C^{\prime \prime}-C^{\prime}\right)}
$$

to calculate $n$ as a function of the molecular weight of the solute, $P M$, and the experimentally known values of freezing point lowerings for two different weights of added solute.

The next contribution to the subject came from another area within the subject of theory of solutions. The study of supersaturated solutions also aroused the interests of the chemists at the second half of the nineteenth century, and required for its development the results collected up till then on freezing points. The Swiss chemist Louis Casimir de Coppet (1841-1911) began working in this area (Figure 3 ), trying to extend Rüdorff's conclusions on freezing points to the study of all aqueous solutions. The extensive freezing point depressions data and temperatures of maximum density he measured and
Table 5. Rüdorff's results for fourteen different solutions of sodium chloride ${ }^{22}$

\begin{tabular}{|c|c|c|c|c|}
\hline MI & $\mathbf{M}_{\mathbf{i}}$ & $\mathbf{T}$ & $\frac{T}{M}$ & $\frac{\mathrm{T}}{\mathrm{M}_{1}}$ \\
\hline $\begin{array}{r}1 \\
3 \\
4 \\
4 \\
6 \\
8 \\
16 \\
12 \\
14 \\
15 \\
16 \\
17 \\
18 \\
19 \\
30\end{array}$ & $\begin{array}{l}27,04 \\
29,06 \\
31,07 \\
33,17 \\
35,29 \\
37,38\end{array}$ & $\begin{array}{c}0,6 \\
0,6 \\
1,2 \\
2,4 \\
3,6 \\
4,8 \\
6,0 \\
7,2 \\
8,4 \\
9,2 \\
9,9 \\
10,6 \\
11,4 \\
12,1 \\
12,8\end{array}$ & 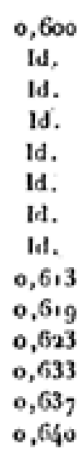 & $\begin{array}{l}0,340 \\
0,34 \\
0,34 \\
0,34 \\
0,3 \% 2 \\
0,349\end{array}$ \\
\hline
\end{tabular}

correlated allowed him to acquire full information on the chemical constitution of most of the salt solutions existing, applying by first time the molecular theory to the analysis of the results. His study constituted, without any doubt, the fullest research on the subject in this early stage. ${ }^{23}$

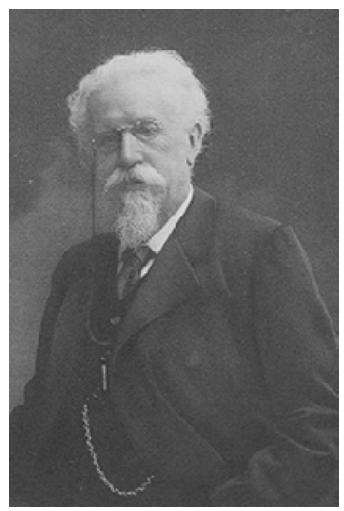

Figure 3. Louis Casimir de Coppet ${ }^{19}$

Through a very detailed experimental programme and complicated calculations, de Coppet concentrated his efforts on explaining the inconsistencies he identified in Rüdorff's results, proposing a new hypothesis that helped to get a unique and solid theory for aqueous solutions. Unlike previous researches, his work included mainly concentrated solutions, prepared with twenty-five different solutes. ${ }^{24}$

De Coppet took up again what previous results had suggested to Rüdorff himself, and other researchers, about the possibility to use the experiments on freezing point depressions to learn about the real state of a salt, anhydrous or hydrated, in solution, but that no one had fully developed. The information made use of the geometric behaviour of one of the two sections of the line in a graph of $K$ vs. $C$, as can be deduced from the shown values in the tables. A quick observation of the results showed that the curves for all aqueous solutions studied, in the short range between $0^{\circ}$ and approximately $4{ }^{\circ} \mathrm{C}$, were generally composed of a first section with the form of the branches of a hyperbola turning its convexity to the axis of the abscissa, followed by other one approximately linear. If this latter section remained parallel to the axis of abscissa, the solute's condition was anhydrous; if on the other hand it had a positive slope, there was the formation of a hydrate. 
De Coppet was able to add a new type to the previously known classification of solutions' behaviours according to their relationship between Blagden's ratio and the weight of dissolved solute (and subsequently with the freezing point lowering), which showed a $K$ decreasing with $C$. The general rules for classifying the salts were now complete (Figure 4): (a) when the reported values for solutions of the same salt are approximately constants within some specific limits of temperature and concentration, it is possible to conclude that the salt pre-exists in them in an anhydrous condition; (b) if they increase with $C$, the salt has formed, at least, one compound with the solvent, and (c) if they decrease with $C$, it could to be a consequence of the presence of a mixture of two or more hydrates of the same salt in solution, that didn't exhibit any chemical interaction between them, and whose relative proportions could change with temperature and the global solution's concentration. This same classification was also valid for the lowering of the temperature of maximum density.

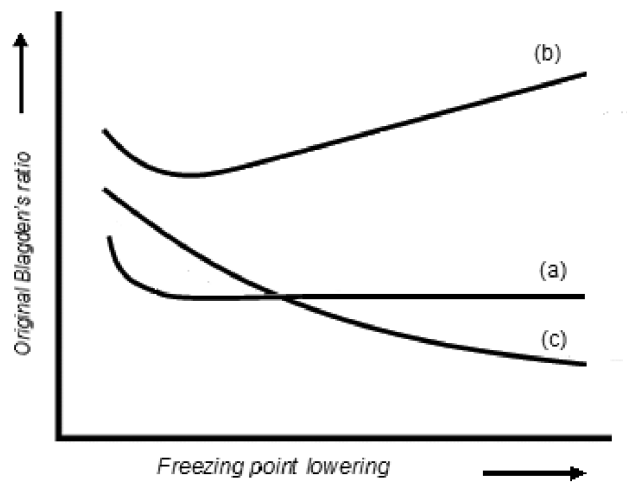

Figure 4. Aqueous salts' solutions according to their freezing point behaviours

Looking for explanations about the inconsistencies raised by the existence of the new class of solutions, de Coppet arrived at important conclusions. He attributed the situation to the simultaneous presence of two or more different hydrates in solution, whose relative proportions changed with both temperature and global composition. According to his results, the necessary occurrence of a gradual decomposition of a determined hydrate could be influenced either by the relative proportion of the solvent, or in other words a changing composition, or by appreciable variations in temperature. For this specific class of circumstances, he concluded that each hydrate lowered the freezing point in the same quantity as it was present alone in the solution, and that the total freezing point lowering would be the sum of that due to each compound separately. This last conclusion quantitatively confirmed almost a century later Blagden's belief on the same subject.

The terms lowering coefficient, $\mathrm{h}_{\mathrm{n}}{ }^{(\mathrm{c})}$, and atomic freezing point lowering, $\mathrm{H}_{\mathrm{n}}{ }^{(\mathrm{c})}$ (which he later changed to molecular depression) that de Coppet introduced to represent the lowering in the temperature per $1 \mathrm{~g}$ and $1 \mathrm{~mol}$ of dissolved salt in 100 grams of water, respectively, allowed him to identify some common behaviours. For example, on comparing the corresponding values to the latter mentioned term for solutions formed under similar conditions, with salts of the same specie (chlorides, nitrates, sulphates, etc.), he found for each family, with very few exceptions, that they were approximately equal, as is shown in Table $6 .{ }^{25}$ Likewise, he observed for the same parameter that the values corresponding to different states of hydratation of the same salt were approximately constant, or that they slightly increased with the number of molecules of water that formed the compound. Similar results were found for the depression of the temperature of maximum density. A quick analysis of the obtained values led him to also establish a rule by which the ratio between both depressions was a fixed and unique characteristic number for the solutions he studied. Nevertheless, he was always very careful and didn't dare to generalize any of his conclusions.

De Coppet was able to notice some additional trends. As an example, he considered that solutions with the same dissolved salt, but with different hydrates, have the same molecular lowerings. Likewise, he observed too that the corresponding values to salts with common ions, as an example potassium chloride, bromide, and iodide, increased with the respective molecular weight. This characteristic trend to look for simple relationships between different variables and the chemical constitution of the compounds could to be due to the influence of Hermann Kopp (1817-1892), one of his professors in chemistry over his doctorate studies at Heidelberg.

\section{SUMMARY: STATE OF THE ART BEFORE RAOULT}

The early developments on cryoscopy didn't happen in a flash, nor were the result of a sole brilliant mind. Initially they arose as a consequence of the study of density of water and salt solutions, but little by little turned into a subject of special interest of their own. In addition to the regular steps that characterized the scientific development, the evolution of the knowledge on this subject was also accompanied by some of the typical facts that usually encircled the establishment of any new law or theory. For example, the occurrence of an incidental fact as the abrupt change in meteorological conditions was a determinant event for allowing Watson to reach the conclusions he derived, which, very probably under other circumstances, would have been considerably and indefinitely delayed. Likewise, it is clear that fortunate deficiencies in the experimental procedures, such as those previously mentioned about Blagden's experimental procedure, contributed to the formulation of a generalized relationship. For another example, the need for finding theory good enough to 'justify' some apparently abnormal results, turned out to be a lucky situation that forced Rüdorff to suggest the existence of hydrated compounds, and so significantly extend the applicability of the initial statement of the law to a lot of more solutions.

The evolution in terminology also was a characteristic fact. In that it was necessary, names as ratio, lowering coefficient, atomic and molecular lowerings were appearing one after another as key elements that contributed to the desirable generalization.

De Coppet didn't establish the subject of cryoscopy, but had prepared its arrival. While a true general law on the freezing point lowering of solutions was still some years in the future, he was sufficiently able to identify in advance the exceptions to what would be later its statement. His results, together with those separately published by the German scientists Clemens Heinrich Lambert von Babo (1818-1899) ${ }^{26}$ and Adolf Wüllner (1835-1908) ${ }^{27}$ also on the lowering effect of the solute's presence but on the vapor pressure of aqueous solutions, constituted themselves as very useful information for the establishment of a general theory.

When Raoult came on the stage of cryoscopy scarcely any generalization worthy of the name had been reached. The main reason for it was the fact that the aqueous solutions were so far the only solutions examined. As only later it would be well known, the marked dissociating action of water not only was responsible for the apparently anomalous behaviour of acid and alkaline solutions, but turned this solvent into the least appropriate one to find any relations in studying these phenomena. However, the analysis of all the results so far began to shed light on the different parameters that must be studied to try to get some class of general law. Factors such as the nature of both solvent and solute, their possible physical association, and the degree of concentration of the respective solutions, would be the object of study in this and later steps on the subject. Names as 
Table 6. Molecular lowerings of freezing points for several solutes in water ${ }^{25}$

Ahathement aromigue du point d' conghlation.

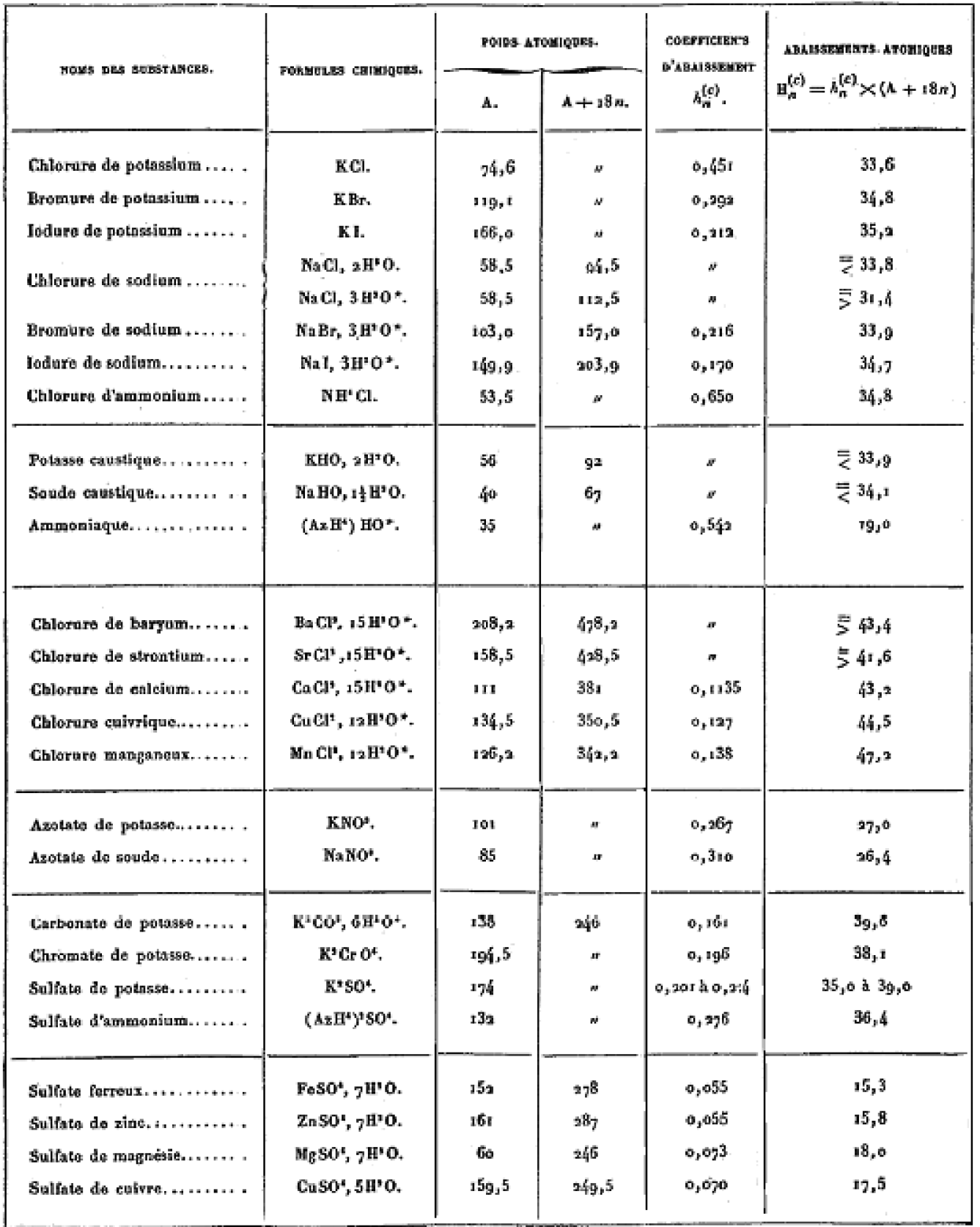

those of Jacobus Henricus van't Hoff (1852-1911) and Svante August Arrhenius (1859-1927) would later make important contributions to the general subject, but it would be Raoult's research on solutions of both organic and inorganic solutes, and different solvents in addition to water, that definitively would open the doors to generalization.

\section{ACKNOWLEDGMENTS}

The Blagden engraving reproduced in the Figure 2 is held at the National Portrait Gallery in London (NPG D14478). I thank for permission to use it in this paper. I am grateful too with Dr. J. C. Brunie, General Secretary of the Société Française de Chimie for his authorization to use the photograph of de Coppet in this paper. I also thank A. Miolo, M. C. Ghetti and S. Talas for providing information on F. Rossetti, and
R. Michaelson and M. Cawley for sending me copies of useful relevant articles. I specially thank Dr. C. Giunta for her important comments about the first drafts of this paper. I am also grateful for the helpful comments did by the anonymous reviewers on a draft of this paper.

\section{REFERENCES}

1. Partington, J. R.; A history of chemistry, MacMillan: London, 1970, vol. II.

2. Bernoulli, D.; Hydrodynamica, sive De viribus et motibus fluidorum commentarii. Opus academicum ab auctore, dum Petropoli ageret, congestum, Dulseckeri: Strassbourg, 1738. http://imgbase-scd-ulp.u-strasbg. fr/displayimage.php?album=250\&pos=0, accessed in June 2007.

3. Coleby, L. J. M.; Ann. Sci. 1953, 9, 101; Partington, J. R.; Chem. Ind. 1937, 56, 819; Bartow, V.; J. Chem. Educ. 1938, 15, 103. 
4. Watson, R.; Anecdotes the life of Richard Watson, Bishop of Landaff, Cadell and Davies: London, 1817. http://www.archive.org/details/anecdotesoftheli00watsuoft, accessed in October 2007.

5. Watson, R.; Phil. Trans. 1770, 60, 325.

6. Watson, R.; Phil. Trans. 1771, 61, 213.

7. Getman, F. H.; Osiris 1937, 3. 69.

8. McNab, J.; Cavendish, H.; Phil. Trans. 1786, 76, 241; 1788, 78, 166.

9. Blagden, Ch.; Phil. Trans. 1788, 78, 277.

10. Blagden, Ch.; Phil. Trans. 1788, 78, 125.

11. Hope, T. C.; Trans. Roy. Soc. Edinburgh 1805, 5, 379.

12. Middleton, W. E. K.; The History of the barometer, Johns Hopkins: Baltimore, 1964.

13. Hardin, W. L.; The rise and development of the liquefaction of gases, MacMillan: London, 1899.

14. Middleton, W. E. K.; A history of thermometer and its uses in meteorology, Johns Hopkins: Baltimore, 1966.

15. Ditte, A.; Étude générale des sels, Dunod et Pinat: Paris, 1906.

16. Anonymus; Proc. Roy. Soc. 1863-1864, 13, viii; Figuier, L.; L'Année Scientifique et Industrielle (Huitième année), Hachette: Paris, 1864.
17. Despretz, C. M.; Compt. Rend. 1837, 5, 19; Ann. Chim. Phys. 1839, 70, 49; 1840, 73, 296; Traité élémentaire de physique, Méquignon-Marvis: Paris, 1836.

18. Dufour, L.; Bull. Soc. Vaudoise Sci. Nat. 1860, 47, 1; Ann. Chim. Phys. 1863, 68, 370; Dufour, H.; Bull. Soc. Vaudoise Sci. Nat. 1893, 29, 211.

19. Casellato, S.; Pigatto, L.; eds.; Professori di materie scientifiche all'Università di Padova nell'ottocento, Lint: Trieste, 1996.

20. Rossetti, F.; Ann. Chim. Phys. 1867, 10, 461; 1869, 17, 370; 1871, 23, 76; Nuovo Cimento 1869, 1, 243; 1869, 2, 73; 1870, 3, 265.

21. Anonymus; Angew. Chem. 1902, 15, 1257.

22. Rudorff, F.; Pogg. Ann. Phys. und Chem. 1861, 114, 63; 1862, 116, 55; Ann. Chim. Phys. 1861, 63, 488.

23. Lespieau, R.; Bull. Soc. Chim. 1913, 13, i.

24. De Coppet, L. C.; Ann. Chim. Phys. 1871, 23, 366; 1872, 25, 502.

25. De Coppet, L. C.; Ann. Chim. Phys. 1872, 26, 98.

26. von Babo, C. H. L.; Üeber die spannkraft des wasserdampfes in salzlösungen, ein beitrag zur static der atome, Freiburg, 1847.

27. Wüllner, A.; Üeber den einfluß des procentgehaltes auf die spannkraft des wasserdampfes aus wässeringen salzlösungen, Inauguraldissertation 1856; Ann. Phys. 1858, 103, 529; 1858, 105, 85, 478; 1859, 106, 632; 1860, 110, 564; Ann. Chim. Phys. 1858, 53, 497; 1859, 56, 249; 1860, 60, 245. 